\title{
Design of Isolated Micro Grid Using Renewable Energy Resources with Energy Storage System via HOMER Software A Case Study of a Thar Community
}

\author{
Mahesh Kumar $^{1}$, Waleed Memon ${ }^{1}$, Amir Mahmood Soomro ${ }^{1}$
}

\begin{abstract}
:
Electricity is major requirement for each individual or group to live a prosper and good life, while unfortunately in Pakistan still there are some areas which does not have provision towards this facility. The microgrid is designed to power up those rural areas of Pakistan which does not have provision of electricity via conventional means. To achieve this feat this paper presents a case study of a Thar community or small village located in Thar, Sindh, Pakistan. The small village comprises of 40 houses, some shops and a primary school. The study area having latitude and longitude of $24052.7^{\prime} \mathrm{N}$ and $70014.4^{\prime} \mathrm{E}$ respectively. The microgrid consists of a Diesel Generator, Photo voltaic solar panels, Batteries and Flywheel systems. The purpose is to find the most optimal solution using different parameters via Homer optimization software.
\end{abstract}

\section{Keywords: Optimization, Photovoltaic, Homer, Energy, Optimization}

\section{Introduction:}

According to World Energy Outlook study by International Energy Association [1], there are 51 million people in Pakistan who does not have access to electricity, from which $63 \%$ people are from rural areas. The cause of this situation is due to energy crisis and huge gap between supply and demand in Pakistan. The reason to quote this energy state problem is that we had relied from past two decades to non-renewable energy resources and till now we are relying on it. While other nations have changed their course from non-renewable energy resources to renewable energy resources for the betterment of environment, to conserve non-renewable energy resources and to tackle the ever increasing demand of energy. In order to achieve the foresaid statement an isolated microgrid is to be designed using PV solar panel and diesel generator with and without energy storage systems to obtain a feasible and optimized solution for the community using homer software by aiming the highest penetration of renewable energy resource in the system.

A research paper was presented on standalone residential PV solar system for Assiut city. In this he proposed an isolated PV panel's based optimized and feasible solution containing an estimated load of 2 $\mathrm{kW}$ (lighting load, washing machine, TV and other small appliances load) and proposed the most feasible and optimized solution [2]. Another isolated microgrid for small community of cholistan using PV panels and bio mass gas as renewable energy resources and calculated the feasibility report via homer software [3].

A research paper was presented consisting a hybrid microgrid system using wind, solar and hydrogen renewable energy resource to meet the load in most feasible and optimized way. They proposed isolated as well as on grid provision in the system, while all cost energy optimization reports

\footnotetext{
${ }^{1}$ Department of Electrical Engineering, Mehran University of Engineering and Technology Jamshoro, 76062, Sindh Pakistan.

Corresponding author: rathii.mahesh@faculty.muet.edu.pk 
were established using homer software [4]. Another research paper as proposed by an Indian author he presented a decentralized micro grid system in India, Kondapalli forest on Indrakeeladri hillocks of Vijayawada using PV panels and wind turbine, for this system the optimized values and feasibility is obtained using homer software [5].

An optimal hybrid renewable system for isolated systems i.e. three remote islands located in Maldives using three different resources PV Panel, Wind Energy and Diesel Generators. The optimization and feasibility levels are achieved by using Particle Swarm Optimization (PSO) technique to calculate the PV panels, Wind Energy and Diesel Generator parameters, Carbon emissions, fuel severity analysis, and solar irradiation for that area [6]. A research paper was proposed by an Iranian author he proposed a hybrid microgrid system for a village located in Iran, currently having diesel generators to meet the load demand. He introduced to incorporate wind and solar renewable energy sources in conjunction with existing diesel generators to obtain a feasible and optimized solution. The system parameters will be defined for standalone as well as on grid configuration to effectively utilize the resources [7].

A distributed microgrid for small community whom there were no conventional power feasibility was available. The proposed microgrid was based on PV arrays, wind energy, small hydro turbine along with battery backup systems, all the feasibility and optimization calculations were performed using homer pro software [8]. Another hybrid microgrid concept using micro hydroelectric (MHP) source and PV arrays to tackle the ever increasing demand of electricity in Indonesia via renewable energy resources. In order to achieve this feat they used homer and matlab software for simulation and calculation to obtain the most feasible and optimized solution [9].A research paper was concluded using a standalone hybrid microgrid system for a university of Mombasa consisting of small appliance load to heavy machinery loads by using PV arrays and wind turbine renewable energy resources. The feasibility and optimization calculations are achieved using homer software [10-14].

\section{Research Methodology}

\subsection{Community Load Profile}

The village consists of 40 houses, few shops and primary school. Unlike urban areas these houses are distant from one another and mostly comprises lighting, fans and domestics electric motors for water pumping. The average estimated load for the community is $535.2 \mathrm{kwh} / \mathrm{d}$ and a peak demand of $61.47 \mathrm{~kW}$. The daily load profile graph was shown in Fig. 1 and monthly average load demand graph is shown in Fig. 2.

\section{Daily Profile}

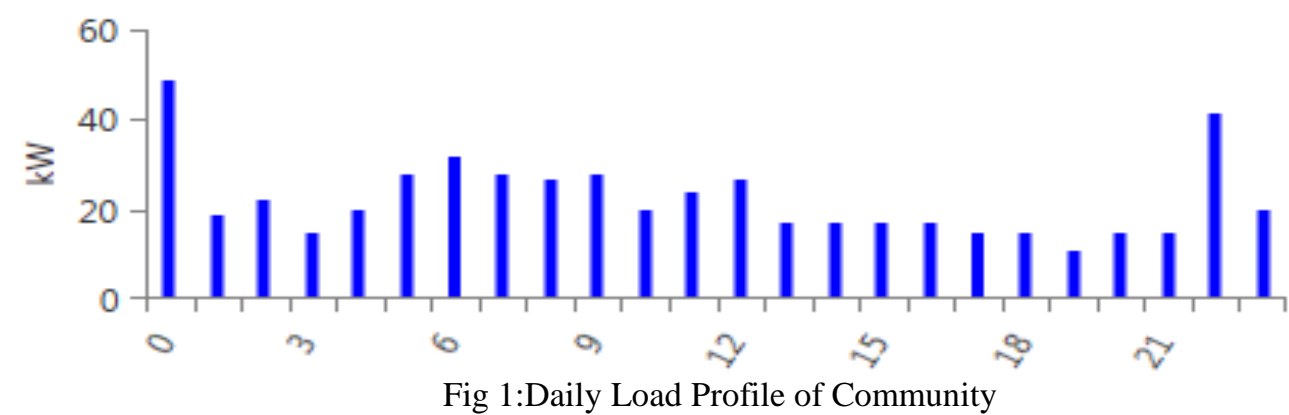

\subsection{Solar PV Module}

The solar irradiance for the described community was calculating using HOMER database system, the location coordinates were 240 52.7' $\mathrm{N}$ latitude and 700 14.4' $\mathrm{E}$ longitude. The scaled annual average and clearance index was calculated by HOMER software. The scaled annual average for the community load was found to be 5.61 $\mathrm{kwh} / \mathrm{m} 2$ per day while average clearance 


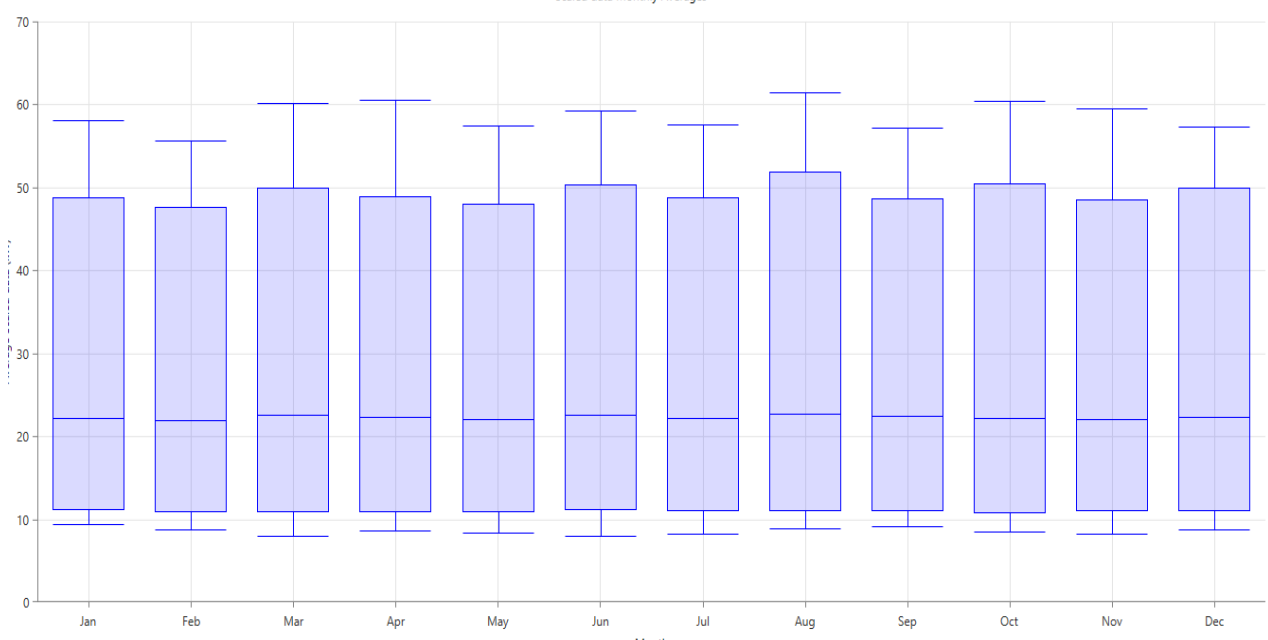

Fig. 2 Monthly Average Load Data of the Village/Community

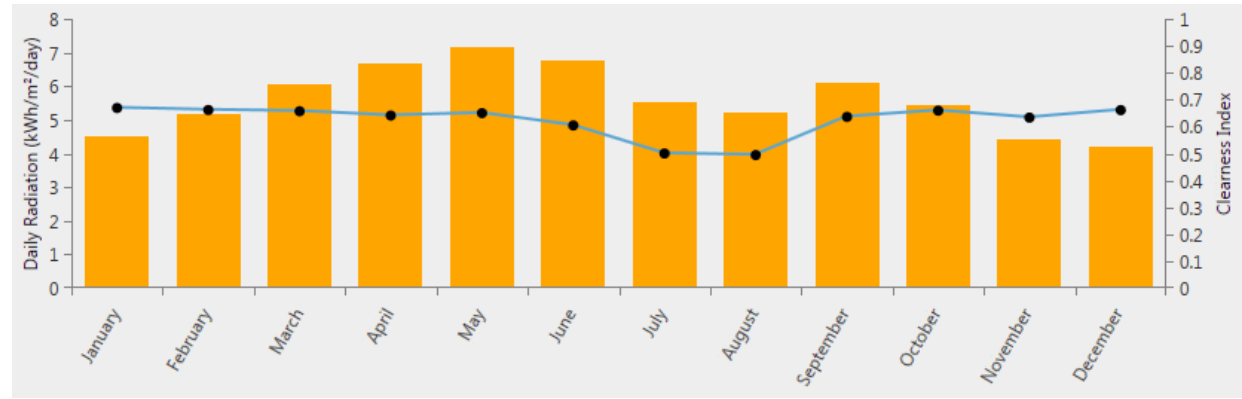

Fig. 3 Solar Irradiance Graph for the Defined Community

index in 0.62. Fig.3 represents the solar irradiance data for the defined community.

\subsection{Battery}

Batteries are used to store electricity generated by renewable energy resource in order to utilize that electricity when renewable energy is not available in case of solar during night time. This to ensure availability of power. The type of battery used here is $83 \mathrm{Ah}, 1 \mathrm{kwh}$, VRLA batteries of 12 volts, with life expectancy of 10 years and operation and maintenance cost of 10 US\$/year. The capital cost of battery is 300 US\$ and Replacement cost is 225 US\$.

\subsection{Converter}

A converter is an electrical device which transforms ac power into dc via rectifier and dc power tp ac via inverter, the converter is used here is a bidirectional inverter/rectifier.
The cost of this bidirectional convertor is $300 \mathrm{US} \$ / \mathrm{kW}$ of power conversion with replacement cost of $225 \mathrm{US} \$ / \mathrm{kW}$. The convertor having $95 \%$ rectification and inversion efficiency while the cost of O\&M is around $15 \mathrm{US} \$$ /year.

\section{Simulation Final Results and Discussions}

The optimization results of microgrid is shown in Fig. 4, the optimization results are acquired using HOMER software. There are two systems compared and analyzed on COE and total NPC. The systems are compared with and without energy storage systems and the results were analyzed and most optimizes solution is acquired in terms of COE and total NPC with the aim of highest renewable energy penetration in the system. The first system comprises only PV modules, Diesel Generator and Convertor as shown in Fig.5. The lowest NPC for the

Sukkur IBA Journal of Computing and Mathematical Science - SJCMS | Vol. 5 No. 1 January - June 2021 @ Sukkur IBA University 
system is 944,156 US\$ while cost of The most optimized solution obtained from electricity per $\mathrm{kWh}$ is $0.374 \mathrm{US} \$$.

The optimization result for the system with energy storage system is obtained and shown in Fig.6, this configuration contains PV module. Diesel Generator, Convertor and ESS (Batteries and Flywheel system).

this configuration is with total net present cost of 644,201 US\$ and cost electricity per $\mathrm{kWh}$ of 0.255 . This system is much feasible in terms of total NPC and COE than the system without ESS, secondly this system has highest renewable energy resource penetration which can be seen in Fig. 7

\begin{tabular}{|c|c|c|c|c|c|c|c|c|c|c|c|c|c|c|c|}
\hline Sensistivity & & Architectur & & & & & Cot & & & stem & & & Gen Set & & \\
\hline $\begin{array}{l}\text { Diesel } \\
\text { FuelPice? } \\
\text { (USSIL) }\end{array}$ & 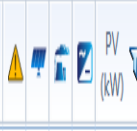 & ${ }_{(k \mathrm{~N})}^{\text {Gen Set }} \nabla$ & $\begin{array}{l}\text { Convether } \\
\text { (kM) }\end{array}$ & 7 Dispatc & $\frac{\mathrm{COE}}{(\mathrm{CSS})}(0)$ & $\frac{N P C}{N S S S \mid} 07$ & $\begin{array}{l}\text { Opereding cos } \\
\text { (USS/y) }\end{array}$ & 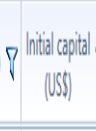 & Ren Fer & 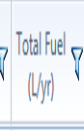 & 7 Hours 5 & $\begin{array}{l}\text { Prodution } \\
(\mathrm{kNh})\end{array}$ & (fuel 7 & 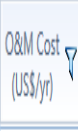 & 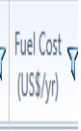 \\
\hline 0.750 & 19:8200 & 60.0 & 10.0 & ll & 1550.374 & 15S954,157 & US5693999 & US597,000 & 7.5 & 60556 & 8760 & 181,181 & 60556 & 10512 & 45,417 \\
\hline 125 & 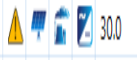 & 600 & 20.0 & d & US50.528 & $15 S 133 \mathrm{M}$ & uss985994. & USSSOOOOOO & 9.21 & 59.586 & 8760 & 177,247 & 59,586 & 10,512 & 74482 \\
\hline 150 & $\Delta \div=30.0$ & 600 & 200 & u & US506065 & ISSTI53M & USS513:4991 & uss60000 & $9: 21$ & 59,586 & 8760 & 177,377 & 59,586 & 10,512 & 89,378 \\
\hline
\end{tabular}

Fig. 4 Optimal solution Table

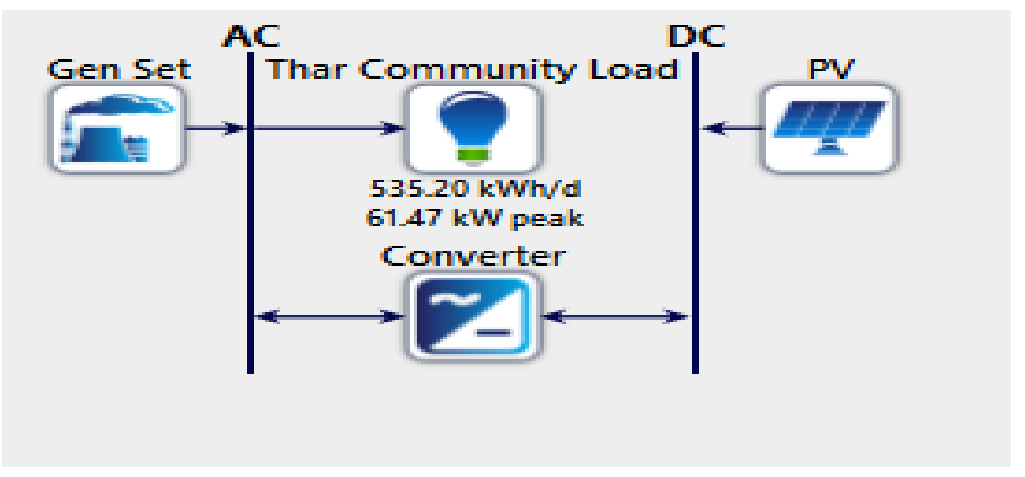

Fig. 5. Systematic Diagram of system without ESS

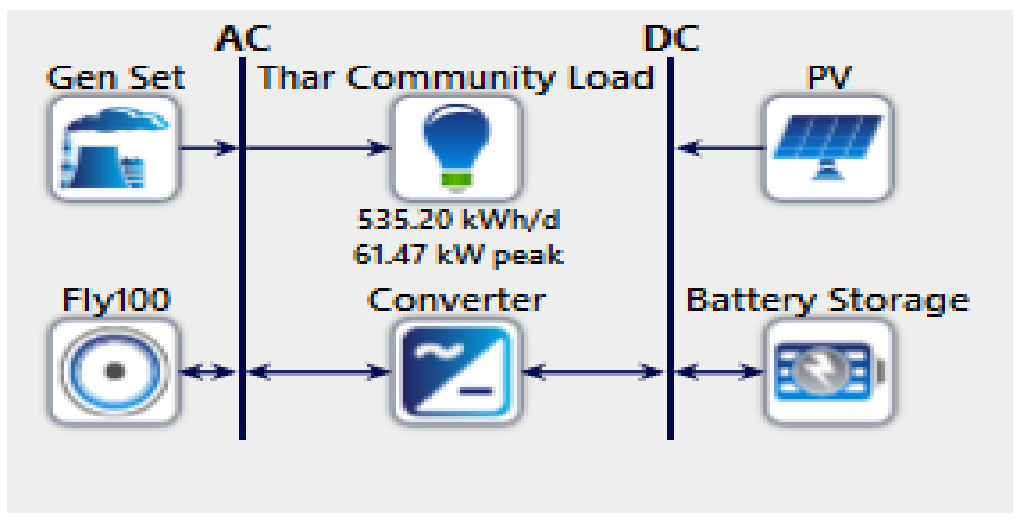

Fig.6. Systematic Diagram with ESS 


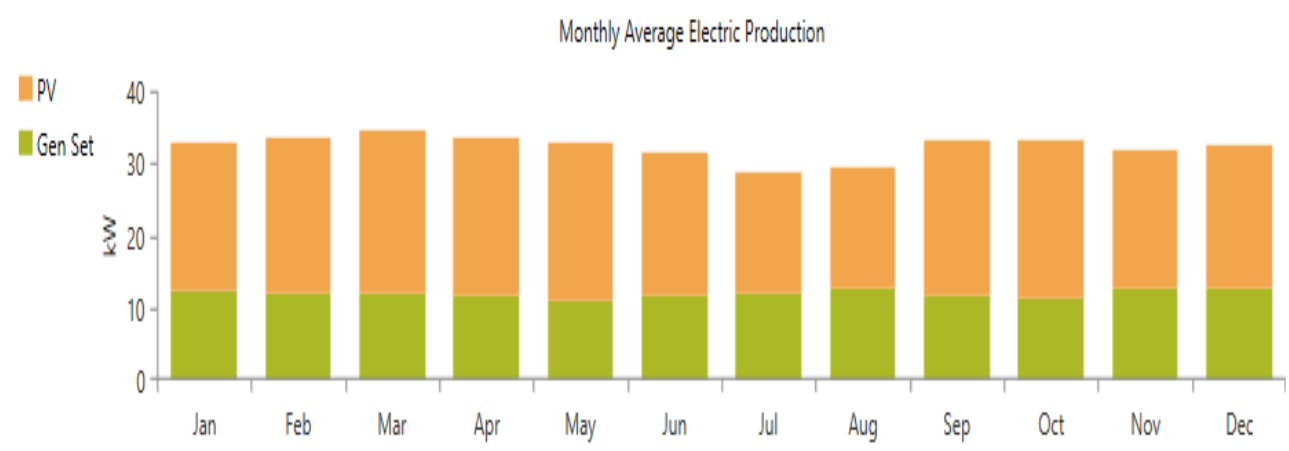

Fig. 7. Electricity production share by PV and Diesel Generator

\section{Conclusion}

The results obtained by HOMER software clearly depicts that the system with energy storage system ESS having lowest total net present cost and lowest cost of energy COE per kWh generated. The system also comprises highest amount of renewable energy resource penetration that of $63 \%$ percent of electricity is generated using PV solar panels while $37 \%$ of electricity is generated via diesel generator. The generation share in terms of $\mathrm{kWh} /$ year for PV panels and by diesel generator was $178,004 \mathrm{kWh} /$ year and 104,427 kWh/year making a total generation of 282,431 $\mathrm{kWh}$ /year. Thus contributing less carbon emission in the environment with lowest possible energy cost. This also fulfils the need to electrify the rural areas where electricity provision in not possible by national grid via hybrid energy resources.

\section{Acknowledgment}

The authors thanks Mehran University of Engineering and Technology Jamshoro for providing research facilities.

\section{References}

[1] Vincietal, S., "Energy Access Outlook 2017: From Poverty to Prosperity," International Energy Agency, Volume 94, No. 3, pp. 116, 2017.
[2] Abdel-Salam, M., Ahmed, A., Amery, M., Swify, M., El-kousy, A. and Sayed, K., 2011, December. Design and implementation of stand-alone residential PV system. In 2011 IEEE Jordan Conference on Applied Electrical Engineering and Computing Technologies (AEECT) (pp. 1-6). IEEE.

[3] Türkay, B.E. and Telli, A.Y., 2011. Economic analysis of standalone and grid connected hybrid energy systems. Renewable energy, 36(7), pp.1931-1943.

[4] Krishna, K.M., 2011, December. Optimization analysis of microgrid using HOMER - a case study. In 2011 Annual IEEE India Conference (pp. 15). IEEE.

[5] Oulis Rousis, A., Tzelepis, D., Konstantelos, I., Booth, C. and Strbac, G., 2018. Design of a hybrid AC/DC microgrid using HOMER Pro: case study on an islanded residential application. Inventions, 3(3), p.55.

[6] Aly, A.M., Kassem, A.M., Sayed, K. and Aboelhassan, I., 2019, February. Design of Microgrid with Flywheel Energy Storage System Using HOMER Software for Case Study. In 2019 International Conference on Innovative 
Trends in Computer Engineering (ITCE) (pp. 485-491). IEEE.

[7] Asrari, A., Ghasemi, A. and Javidi, M.H., 2012. Economic evaluation of hybrid renewable energy systems for rural electrification in Iran-A case study. Renewable and Sustainable Energy Reviews, 16(5), pp.3123-3130.

[8] Hafez, O. and Bhattacharya, K., 2012. Optimal planning and design of a renewable energy based supply system for microgrids. Renewable Energy, 45, pp.7-15.

[9] Nazir, R., Laksono, H.D., Waldi, E.P., Ekaputra, E. and Coveria, P., 2014. Renewable energy sources optimization: A micro-grid model design. Energy Procedia, 52, pp.316327.

[10] Sandeep, G. and Vakula, V.S., 2016, March. Optimal combination and sizing of a standalone hybrid power system using HOMER. In 2016 International Conference on Electrical, Electronics, and Optimization Techniques (ICEEOT) (pp. 4141-4144). IEEE.

[11] Gilal, A. R., Jaafar, J., Omar, M., Basri, S., \& Waqas, A. (2016). A rule-based model for software development team composition: Team leader role with personality types and gender classification. Information and Software Technology, 74, 105-113.

[12] Gilal, A. R., Jaafar, J., Capretz, L. F., Omar, M., Basri, S., \& Aziz, I. A. (2018). Finding an effective classification technique to develop a software team composition model. Journal of Software: Evolution and Process, 30(1), e1920.

[13] Kumar, M., Das, B., Baloch, M. H., Nallagownden, P., Elamvazuthi, I., \& Ali, A. (2019). Optimal Placement and Sizing of Distributed Generators and Distributed-Static Compensator in Radial Distribution System: Distributed Generators and Distributed-Static Compensator. International Journal of Energy
Optimization and Engineering (IJEOE), 8(1), 47-66.

[14] Kumar, M., Nallagownden, P., \& Elamvazuthi, I. (2017). Optimal placement and sizing of renewable distributed generations and capacitor banks into radial distribution systems. Energies, 10(6),811. 